\title{
Imageless computer assisted navigation in ceramic-on-ceramic total hip arthroplasty vs. manual approach: a single-centre retrospective study
}

\author{
J. McLoughlin MPharm ${ }^{1}$, M. O. Mathew MS (Orth) FRCS Glas (Tr \& \\ Orth) ${ }^{2}$ and S. Grant MB ChB(Hons) FRCS(Orth) MRCS DHPE ${ }^{2}$ \\ ${ }^{1}$ University of Glasgow \\ ${ }^{2}$ NHS lanarkshire, University Hospital Hairmyres \\ johnmcloughlin267@gmail.com, \\ stephen.grantelanarkshire.scot.nhs.uk, \\ Mo.Mathew@lanarkshire.scot.nhs.uk
}

\begin{abstract}
Background: Acetabular cup positioning is vital to the long-term survivorship of total hip arthroplasty (THA). Malalignment has been linked to dislocation, wear and osteolysis. Although there are many studies demonstrating the reduction in variability of cup positioning with computer-assisted techniques, there are relatively few reporting long-term patient reported outcomes and revision rates. Aim: The aim of this study was to review whether those patients who underwent navigated THA had better long-term survivorship or better patient reported outcomes. Methods: We compared revision rates and Oxford hip scores of 152 THAs (47 navigated and 105 non-navigated) performed at a single site between 2003 and 2008, with a minimum follow-up of 10 years. Results: 9 of the non-navigated and none of the navigated hips were revised at 10 year follow-up $(\mathrm{p}=0.057)$. There were no observable differences in 10-year Oxford hip scores between the navigated and non-navigated hips, 44.82 and 43.38 respectively. Conclusion: With respect to the rate of revision, although statistical significance was not achieved, it can be shown from our data that there was a clinically significant reduction in revision rates with navigated vs. non-navigated techniques. More data with higher patient numbers in the navigated cohort may be required to validate the results of our study.
\end{abstract}




\section{Introduction}

Total hip arthroplasty (THA) is one of the most commonly performed and successful surgical interventions of the 21st century, with success rates in excess of $90 \%$ demonstrated $(1,2)$. Component orientation has been shown to be a significant factor in determining long-term outcomes following THA. Poor orientation has been linked with increased wearing of components, migration of the acetabular component and impingement (3-5). Several trials have also shown the link between malalignment of the acetabular cup and leg length discrepancy, osteolysis and dislocation $(6,7)$. Several factors, such as variable pelvic positioning of patients on the table, mean free hand techniques lead to significant variability in cup placement(8). Computer assisted surgery (CAS) is growing in popularity as a technique to minimise error in cup placement. There are two variations of this. Imagebased systems which rely on pre-operative collection of images using computed tomography and imageless systems, which use intra-operative orientation data to build up a 3-D anatomical image, using bony landmarks(9). Imageless navigation is the focus of this study. A study by Kalteis et al.(10) showed that using imageless navigation led to a significant increase in acetabular component placement in the 'safe zone' (defined by Lewinnek et al.(11) as inclination and anteversion of $40^{\circ} \pm$ $10^{\circ}$ and $15^{\circ} \pm 10^{\circ}$, respectively). Moskal et el. (12) published a systematic review showing significantly fewer dislocations with navigated techniques as a result of more 'safe' placements. However, the authors concluded that there is an obvious lack of prospective randomized trials, a poor congruency in the reported data and a limited number of patients included in those studies. The results of that evidence-based analysis demonstrated a clear need for further trial data to define or determine the role of navigation in THA. Although many studies compare navigated vs. manual techniques in terms of cup placement accuracy, relatively few report long-term outcomes of the impact of this for patients. In this study, we wanted to focus on patient reported outcomes and the total number of revisions over a ten-year period and quantify the benefit of using navigation.

\section{Patients and Methods}

We conducted a retrospective analysis of 145 patients who underwent a total of 152 (47 navigated, 105 non-navigated) total hip replacements. These were performed at a single site, University Hospital Hairmyres, Eaglesham Road, East Kilbride, G75 8RG. A total of seven surgeons were involved in performing the operations. One surgeon, this study's senior author, performed all the navigated THAs. We collected data from medical records, operating notes and retrospectively reviewing follow up clinic notes. The minimum time to follow up was 10 years (median 11.33 years). Patient reported outcomes were quantified as Oxford hip scores(13), which were collected pre-operatively, 1 year, 5 year and 10 year post-operatively. All patients received Excia ${ }^{\circledR}$ (BBraun) hip stems and either navigated or non-navigated Plasmacup ${ }^{\circledR}$ (BBraun) acetabular Cups. All patients received Biolox ${ }^{\circledR}$ (Ceramtec) femoral head components. Navigation was performed using the imageless Orthopilot ${ }^{\circledR}$ (BBraun) system. Statistical analysis was carried out with Fisher's Exact Test using SPSS (IBM Corp. Released 2016. IBM SPSS Statistics for Windows, Version 24.0. Armonk, NY: IBM Corp). 


\section{Results}

There were no revisions in the group of navigated hips at 10 year follow up vs. 9 revisions in the non-navigated $(\mathrm{p}=0.057)$. The reasons for revision in the non-navigated cohort were as follows: pelvic discontinuity-1, acetabular liner fracture-2 (Fig. 1), malposition-1, thigh/groin pain-2, periprosthetic fracture-2, and dislocation-1.

When comparing prosthesis issues, there were some observable differences between the groups. The results were as follows: five (10.64\%) patients from the navigated group experienced thigh/groin pain, vs. thirteen $(12.4 \%)$ of the non-navigated group. There were also some marginal differences in the rates of prosthesis squeaking between the two groups, two (4.2\%) patients from the navigated group had this issue vs. five $(4.76 \%)$ from the non-navigated hips. In the navigated group there was one patient with a deep wound infection requiring wash out and one patient with residual foot-drop following nerve damage. There were no observable differences in 10-year Oxford hip scores (Table 1) between the navigated and non-navigated hips, 44.82 and 43.38 respectively.

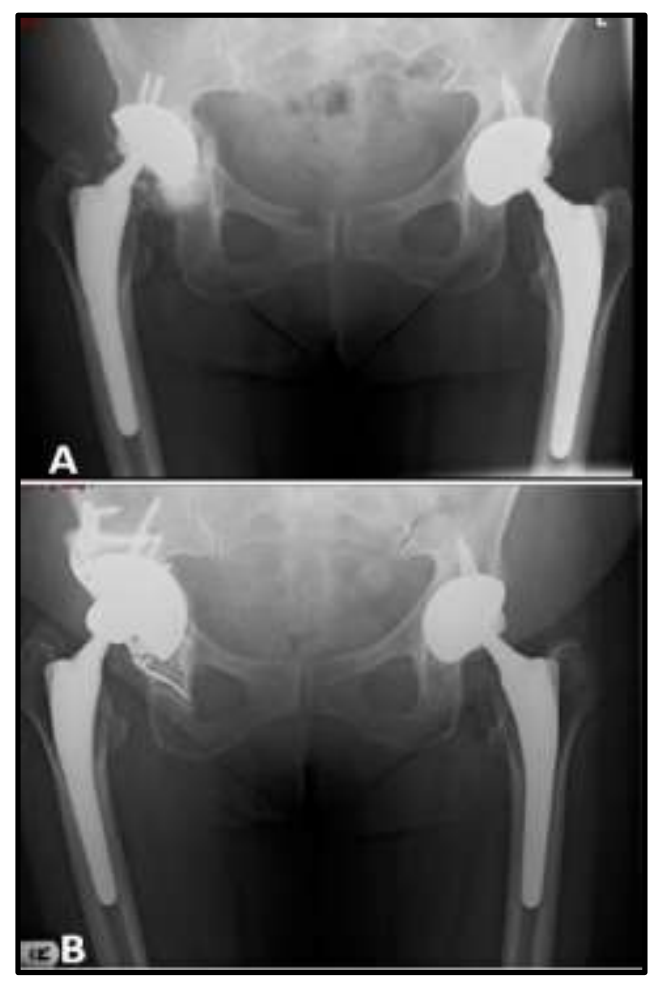

Figure 1. A-B (A) Radiograph taken 6 years post-op in non-navigated THA showing acetabular liner fracture (B) Same patient following revision and repair of pelvic discontinuity 


\section{Discussion}

Computer assisted navigation has shown repeatedly to allow more accurate cup placement with less variability versus non-navigated techniques $(10,14-18)$. From the knowledge that accurate placement leads to less wear, dislocation and osteolysis, we can indirectly infer that this will reduce revision rates and improved patient outcomes post-operatively. We have shown in this study a direct link between the use of navigated techniques and an observable difference in revision rates. Although statistical significance in revisions could not be shown at 10-year follow up, we feel as though our data shows a clinically significant benefit using imageless navigation for THA. Our data also suggests there is only a marginal benefit in using navigation for patient reported outcomes. To truly validate the results of our study, bigger patient numbers are required in the navigated cohort of patients.

\begin{tabular}{|l|ll|}
\cline { 2 - 3 } \multicolumn{1}{c|}{} & Navigated group & Non-navigated \\
\hline Pre-op & 14.92 & 15.9 \\
1yr post-op & 37.66 & 40.54 \\
5yr post-op & 40.73 & 40.30 \\
10yr post-op & 44.82 & 43.38 \\
\hline
\end{tabular}

Table 1. Mean Oxford hip scores collected pre-op, $1 \mathrm{yr}$, $5 \mathrm{yr}$ and $10 \mathrm{yr}$ post op. Scores were reported by patients at scheduled review. Guide: Score 0-19: May indicate severe arthritis. Highly likely patient will require surgical intervention. Score 20-29: Indicates severe hip arthritis, candidate for X-ray/orthopaedic review. Score 30-39: Indicates mild-moderate arthritis. Candidate for non-surgical intervention. Score 40-48: Satisfactory joint function.

\section{References}

1. Havelin LI, Engesaeter LB, Espehaug B, Furnes O, Lie SA, Vollset SE. The Norwegian Arthroplasty Register: 11 years and 73,000 arthroplasties. Acta orthopaedica Scandinavica. 2000;71(4):337-53.

2. Learmonth ID, Young C, Rorabeck C. The operation of the century: total hip replacement. The Lancet. 2007;370(9597):1508-19.

3. DiGioia AM, Jaramaz B, Plakseychuk AY, Moody JE, Nikou C, LaBarca RS, et al. Comparison of a mechanical acetabular alignment guide with computer placement of the socket. The Journal of Arthroplasty. 2002;17(3):359-64.

4. Komeno M, Hasegawa M, Sudo A, Uchida A. Computed tomographic evaluation of component position on dislocation after total hip arthroplasty. Orthopedics. 2006;29(12):1104-8.

5. Wan Z, Boutary M, Dorr LD. The Influence of Acetabular Component Position on Wear in Total Hip Arthroplasty. The Journal of Arthroplasty. 2008;23(1):51-6.

6. De Haan R, Campbell PA, Su EP, De Smet KA. Revision of metal-on-metal resurfacing arthroplasty of the hip. The Journal of Bone and Joint Surgery British volume. 2008;90-B(9):1158-63. 
7. Kennedy JG, Rogers WB, Soffe KE, Sullivan RJ, Griffen DG, Sheehan LJ. Effect of acetabular component orientation on recurrent dislocation, pelvic osteolysis, polyethylene wear, and component migration. The Journal of Arthroplasty. 1998;13(5):530-4.

8. Saxler G, Marx A, Vandevelde D, Langlotz U, Tannast M, Wiese M, et al. The accuracy of free-hand cup positioning--a CT based measurement of cup placement in 105 total hip arthroplasties. Int Orthop. 2004;28(4):198-201.

9. Gandhi R, Marchie A, Farrokhyar F, Mahomed N. Computer navigation in total hip replacement: a meta-analysis. International Orthopaedics. 2009;33(3):593-7.

10. Kalteis T, Handel M, Bäthis H, Perlick L, Tingart M, Grifka J. Imageless navigation for insertion of the acetabular component in total hip arthroplasty. The Journal of Bone and Joint Surgery British volume. 2006;88-B(2):163-7.

11. Lewinnek GE, Lewis JL, Tarr R, Compere CL, Zimmerman JR. Dislocations after total hipreplacement arthroplasties. The Journal of bone and joint surgery American volume. 1978;60(2):21720.

12. Moskal JT, Capps SG. Acetabular Component Positioning in Total Hip Arthroplasty: An Evidence-Based Analysis. The Journal of Arthroplasty. 2011;26(8):1432-7.

13. Wylde V, Learmonth ID, Cavendish VJ. The Oxford hip score: the patient's perspective. Health and quality of life outcomes. 2005;3:66-.

14. Lass R, Kubista B, Olischar B, Frantal S, Windhager R, Giurea A. Total Hip Arthroplasty Using Imageless Computer-Assisted Hip Navigation. The Journal of Arthroplasty. 2014;29(4):786-91.

15. Hohmann E, Bryant A, Tetsworth K. A comparison between imageless navigated and manual freehand technique acetabular cup placement in total hip arthroplasty. J Arthroplasty. 2011;26(7):1078-82.

16. Leenders T, Vandevelde D, Mahieu G, Nuyts R. Reduction in variability of acetabular cup abduction using computer assisted surgery: a prospective and randomized study. Computer aided surgery : official journal of the International Society for Computer Aided Surgery. 2002;7(2):99-106.

17. Parratte S, Argenson JN. Validation and usefulness of a computer-assisted cup-positioning system in total hip arthroplasty. A prospective, randomized, controlled study. The Journal of bone and joint surgery American volume. 2007;89(3):494-9.

18. Lin F, Lim D, Wixson RL, Milos S, Hendrix RW, Makhsous M. Limitations of imageless computer-assisted navigation for total hip arthroplasty. J Arthroplasty. 2011;26(4):596-605. 